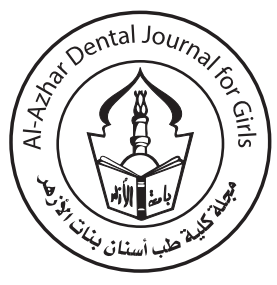

\title{
Effect of Apple Vinegar as a Final Irrigating Solution on Fracture Resistance and Microhardness of Radicular Dentin
}

\author{
Wesam M. Mahmoud ${ }^{1 *}$, Wael H. Kamel ${ }^{2}$, Heba A. Sharaf El Din ${ }^{3}$
}

Codex : 09/21.10

azhardentj@azhar.edu.eg

http://adjg.journals.ekb.eg

DOI: $10.21608 /$ adjg.2021.76140.1377

Restorative Dentistry

(Removable Prosthodontics, Fixed

Prosthodontics, Endodontics, Dental Biomaterials, Operative Dentistry)

\section{KEYWORDS}

Irrigation, Fracture resistance, Microhardness.

\begin{abstract}
PURPOSE: assessment of the fracture resistance and microhardness of radicular dentine following irrigation with apple vinegar as a final rinse. MATERIAL AND METHODS: fifty extracted human lower premolars, in accordance to the inclusion criteria were chosen. All lower premolars were decoronated then prepared using M3 ProGold rotary files and irrigated with $2.6 \% \mathrm{NaOCl} 2 \mathrm{ml} / 1 \mathrm{~min}$. Then all samples were distributed randomly into 2 main experimental groups (20 samples each) depending on the final rinse. Group I: irrigated with Apple vinegar (AV), Group II: irrigated with 17\% Ethylenediamine tetra acetic acid (EDTA) and a Control group (10 samples): irrigated with sterile saline. All samples were prepared to be subjected to either fracture resistance or microhardness tests. The universal testing machine was used to assess fracture resistance. While the Vickers microhardness test was used to determine microhardness. RESULTS: In terms of fracture resistance, the results revealed that group II (EDTA) had a statistically significant reduction in fracture resistance, compared to group I (Apple vinegar), as well as the control group (saline). However, there was no statistically significant difference between group I (Apple vinegar) and control group (saline). While there was no statistically significant difference in total microhardness between the two main experimental groups, there was a statistically significant reduction in microhardness in the experimental groups as compared to the control group. CONCLUSIONS: Regarding fracture resistance, apple vinegar shows better results than $17 \%$ EDTA. While, it is comparable to $17 \%$ EDTA in microhardness of radicular dentine.
\end{abstract}

- Paper extracted from Master thesis titled "Effect of Apple Vinegar as A Final Irrigating Solution on Fracture Resistance and Microhardness of Radicular Dentin."

1. Dentist at Ministry of Health, Egypt

2. Professor of Endodontic Department, Faculty of Dental Medicine for Girls, Al-Azhar University, Cairo, Egypt

3. Lecturer of Endodontics, Department of Endodontics, Faculty of Dental Medicine for Girls, Al-Azhar University, Cairo, Egypt.

* Corresponding author email: wesam080914@gmail.com 


\section{INTRODUCTION}

Endodontic treatment is successful when bacteria capable of generating an intraradicular or extraradicular infection are completely eliminated and debris that accumulates on the wall of the canal creating an amorphous layer that is called smear layer. Endodontic instrumentation should always be accompanied by plenty of irrigation to accomplish chemical, mechanical, and biological effects. The ideal endodontic treatment or retreatment is based on a combination of proper instruments, irrigation, and canal obturation ${ }^{(1)}$

Chemical adjuncts as irrigation are the key cause for facilitating the healing of pulp-periapical diseases among these three phases. This is because the irrigant can remove necrotic tissue remnants and disinfect canals, allowing germs to be eliminated or reduced, especially in teeth with complex internal anatomy. To date, a wide range of irrigants have been employed for this purpose. The gold standard is $\mathrm{NaOCl}^{(2)}$.

The most often used irrigating solution is sodium hypochlorite $(\mathrm{NaOCl})$, it has the same disinfection efficacy of chlorine gas but on the other hand it has less hazards than it in handling and storing. It has excellent dissolution ability of organic compounds in dentine. Moreover, it has strong antimicrobial effect against bacteria also those found in biofilms, viruses and has better anti-fungal effect. On the other hand, it has certain limitations as lack of substantivity, inability for smear layer removal. As a result, alternative chelating agents such as ethylenediaminetetraacetic acid (EDTA) or natural irrigants are sought to eliminate the smear layer discovered during mechanical instrumentation. ${ }^{(3-7)}$.

The use of chelating chemicals during biomechanical root canal preparation improves the removal of the smear layer and increases the irrigant's access to the dentinal tubules, allowing for appropriate disinfection. It also decreases dentin microhardness, making endodontic instruments more effective. (EDTA) is a commonly used chelating agent that dissolves inorganic components and gives ad- ditional benefits, as well as being useful in preparing teeth with calcified canals and providing easy access for root canal armamentarium. In addition, instrument corrosion is negligible or non-existent. Because of its potency against live bacteria, it has various additional beneficial effects as an antibacterial agent. ${ }^{(8,9)}$.

On the other hand its effect on the inorganic components by chelation of calcium ions which is the main component of hydroxyapatite crystals is vigorous and can affect dentine mechanical properties decreasing fracture resistance, flexural strength and microhardness of radicular dentine, as dentine is mainly formed of $70 \%$ inorganic components and only $20 \%$ organic that explains why EDTA causes more reduction in dentine microhardness and fracture resistance than $\mathrm{NaOCl}^{(10,11)}$.

The search for natural irrigants as apple vinegar has been introduced to minimize the harmful effect of EDTA on dentin and periapical tissues. Using apple vinegar as irrigant in the chemo-mechanical process has been proposed due to its promising results that are similar to EDTA. It has a high biocompatibility because it contains a significant amount of malic acid, which is responsible for the majority of its therapeutic actions, including antiinflammatory, antibacterial, antioxidant, antifungal, and anticarcinogenic properties (12-15). Recently, apple vinegar has been used in smear layer removal, and it was concluded that there was no difference in smear layer removal when either EDTA or apple vinegar were used ${ }^{(16)}$.

The development of natural irrigants for endodontic irrigation isn't only for its antimicrobial activity, but also for being low toxic to vital tissues. So, the need for using them to try to increase dentine fracture resistance, flexural strength, ultimate tensile strength by the presence of collagen cross links and hydrogen bonds, so improving bond strength, increasing tissue stability against collagenase degradation. ${ }^{(17-19)}$. For these reasons our study aimed to assess the fracture resistance and microhardness of radicular dentine following irrigation with apple vinegar as a final rinse. 


\section{MATERIAL AND METHODS}

\section{Samples selection and preparation:}

This study used fifty freshly extracted mandibular premolars. The teeth were pulled for periodontal or orthodontic causes. The teeth were selected according to the following criteria; they have single rooted canal system, no calcifications or curved structure, they have completely formed apices. Research ethics committee approval was obtained from Faculty of Dental Medicine for Girls, AlAzhar University (code: REC-EN-21-04).

The root length was standardized to $14 \mathrm{~mm}$ after each tooth was beheaded at the cement-enamel junction with a diamond disc under continual water cooling. Canal patency and working length determination was done by passing $\mathrm{K}$ file size 10 until just visible from the apical foramen then subtracting $1 \mathrm{~mm}$ to determine the working length. M3 Pro Gold files system were used. At a rotational speed of $350 \mathrm{rpm}$ and a torque regulated that was changed according to the manufacturer's instructions for each file used, a 16:1 reduction gear hand piece powered by a torque-controlled electric motor (E-CUBE TM) was used for root canal preparation. A set of 3 instruments were used. All experimental groups were irrigated with $2 \mathrm{ml} 2.6 \% \mathrm{NaOCl}$ solution for one minute followed by the assigned final irrigating solution $5 \mathrm{ml}$ for $3 \mathrm{~min}$.

An endodontic irrigating syringe with a 27-gauge side vent irrigating needle was used to administer the irrigating fluid, which was $2 \mathrm{~mm}$ short of the working length. After three in-and-out motions, the instruments were inspected for damage and the flutes of the utilized instruments were cleaned with gauze soa ked in $70 \%$ ethyl alcohol.

Samples were then divided into two main experimental groups (I and II) according to the final irrigation used in this study, and one control group.

Group (I): (N=20) Samples were irrigated with apple vinegar as a final irrigating solution.
Group (II): (N=20) Samples were irrigated with 17\% EDTA solution as a final irrigating solution.

Control group: $(\mathbf{N}=10)$ Samples were irrigated with saline solution.

Samples were then prepared to assess either fracture resistance or microhardness evaluation.

\section{Preparation for the fracture resistance test:}

After completion of root canal preparation, the roots were covered with wax to a level of $2 \mathrm{~mm}$ from the cervical edge to create a thickness of $0.2-0.3 \mathrm{~mm}$ of wax. Then, the roots were vertically mounted in brass mould filled with chemical cured acrylic resin (Acrostone Manufacture, Cairo, Egy) in standard cylinders and adapted for the root fracture test in the Universal Testing Machine. After chemical cured acrylic resin polymerization, the roots were removed from the mould and placed in hot water for two seconds for wax removal. Condensation silicon impression material with a light bodied consistency (Silaxil it, lascod, Italy) was mixed following the manufacturer's instructions and inserted into the artificial root shaped space, which was then repositioned under light pressure until the cervical boundary was marked. This initial procedure was aimed to replicate the periodontal ligament with a thickness of 0.2-0.3 mm.

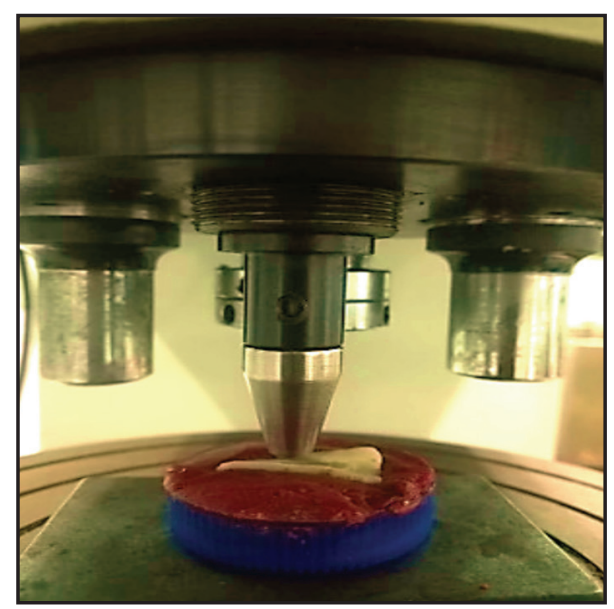

Figure (1) Showing universal testing machine used for evaluating fracture resistance of radicular dentine. 


\section{Fracture resistance test procedure:}

The acrylic blocks, including the roots, were attached by tightening screws on the lower fixed compartment of a Universal Testing Machine (Model 3345; Instron Industrial Products, Norwood, MA, USA) with a loadcell of $5 \mathrm{kN}$. Computer software (Instron ${ }^{\circledR}$ Bluehill Lite Software) was used to record the data. A pointed tip metal rod was fastened directly to the upper plate of the machine. A sharp tip metal rod was attached immediately over the canal entrance of each root on the machine's upper plate, which was subjected to a progressively increasing vertical load $(0.5 \mathrm{~mm} / \mathrm{min})$ until the fracture occurred. An audible fracture indicated the load at failure, which was confirmed by a dramatic drop in the load-deflection curve recorded with computer software (Instron ${ }^{\circledR}$ Bluehill Lite Software).and this value was recorded in Newtons.

\section{Preparation for the microhardness evaluation (Vickers hardness test):}

The collected fractured halves of each root were embedded horizontal in chemical cured acrylic resin (Acrostone, Cairo, Egy) in standard cylinders and adapted for hardness test in such way the dentine surface exposed to Vickers indenter of hardness testing machine. Specimens were polished by sand paper disc (Picodent, Germany) to get smooth and polished surface for Vickers hardness test.

\section{Microhardness Test procedure:}

The surface micro-hardness of the specimens was evaluated using a Vickers diamond indenter and a 20X objective lens on a Digital Display Vickers Micro-hardness Tester (Model HVS-50, Laizhou Huayin Testing Instrument Co., Ltd. China). For 20 seconds, a load of $200 \mathrm{~g}$ was applied to the specimens' surface. On each third of the dentin surface of the root specimen, three indentations were created 200um from the canal lumen, evenly spaced around a circle, and not closer than $0.5 \mathrm{~mm}$ to the neighbouring indentations. The indentations' diagonal lengths were measured using the built- in scaled microscope, and Vickers values were converted into micro-hardness values.

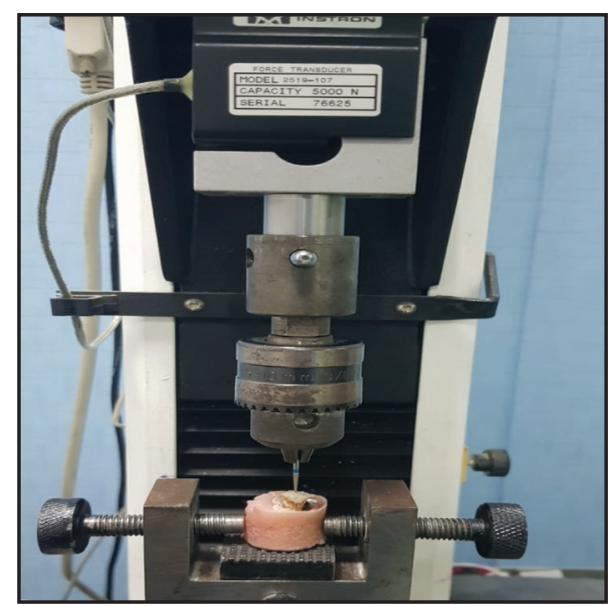

Figure (2) Vickers microhardness testing machine used for evaluating microhardness of radicular dentine

\section{Statistical analysis}

IBM ${ }^{\circledR}$ SPSS $®$ Statistics Version 25 was used for statistical analysis. The mean and standard deviation of numerical data were presented. The data distribution was checked for normality using the Kolmogorov-Smirnov and Shapiro-Wilk tests. Parametric data were analysed using one-way ANOVA followed by Tukey post hoc test for multiple group comparisons, and repeated measures ANOVA when comparing the microhardness between the three levels within the same groups. The significance level was set at $\mathrm{P} \leq 0.05$ within all tests.

\section{RESULTS}

The result of normality test KolmogorovSmirnov and Shapiro-Wilk tests for fracture resistance and microhardness in studied groups revealed that the data is normally distributed ( $\mathrm{p}$ value $>0.05$ ).

\section{Fracture resistance results:}

In terms of fracture resistance, the results showed that group II (EDTA) had a statistically significant lower fracture resistance than group I (Apple vinegar) and the control group (saline). However, no statistically significant difference was found between group I (apple vinegar) and the control group (saline) (Table 1, fig. 3). 
Table (1) The mean, SD of fracture resistance comparing the three studied group (Group I, II and control group)

\begin{tabular}{cccccccc}
\hline & \multicolumn{2}{c}{$\begin{array}{c}\text { Group I } \\
\text { Apple vinegar }\end{array}$} & \multicolumn{2}{c}{$\begin{array}{c}\text { Group II } \\
\text { EDTA }\end{array}$} & \multicolumn{2}{c}{$\begin{array}{c}\text { Control group } \\
\text { Saline }\end{array}$} & \multicolumn{2}{c}{$\boldsymbol{P}$ value } \\
\cline { 2 - 7 } & Mean & SD & Mean & SD & Mean & SD & \\
\hline Fracture resistance & $344.24^{\mathrm{a}}$ & 23.7 & $277.34^{\mathrm{b}}$ & 39.13 & $342.47^{\mathrm{a}}$ & 19.46 & $<0.001$ \\
\hline
\end{tabular}

Small letters denote significance between groups

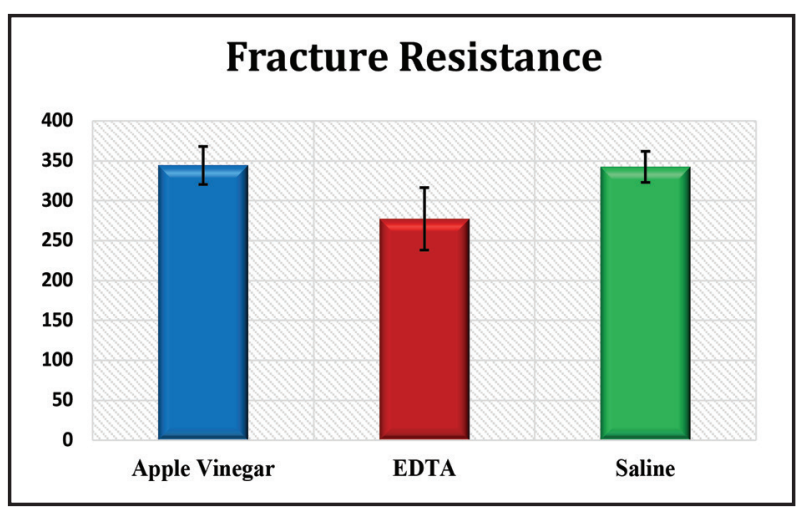

Figure (3) Bar Chart Comparing fracture resistance between the three studied group.

Microhardness results: (Table 2), Fig. 4).

At the cervical and middle levels; The results revealed that there was no statistically significant difference in microhardness between groups I (apple vinegar) and II (EDTA), but a statistically significant difference existed between both experimental groups (I, II) and the control group (saline) (p value $>0.001)$.
At the apical level; The results revealed a statistically significant difference in microhardness between the two main experimental groups (I, II) and the control group ( $\mathrm{p}$ value $=0.009)$.

Regarding microhardness results within each group. Apple vinegar group; statistically significant difference between cervical level compared to middle and apical level ( $p$ value $<0.001$ )

However, within the EDTA group; statistically significant decrease in microhardness in middle, apical levels compared to cervical level ( $P$ value $<0.001,0.009)$, while no significant difference between apical and middle levels $(P$ value $>0.001)$.

Moreover, within the saline group; statistically significant decrease in microhardness in middle, apical levels compared to cervical level ( $P$ value $<0.001,0.002)$, while no significant difference between apical and middle levels $(P$ value $>0.001)$.

While, in total microhardness There was statistically no significant difference between the two main experimental groups, however experimental groups had a statistically significant lower microhardness than the control group.

Table (2) Represent the mean, SD and median of Microhardness comparing the three studied group (Group I, II and control group) at cervical, middle and apical levels.

\begin{tabular}{|c|c|c|c|c|c|c|c|}
\hline & \multicolumn{2}{|c|}{$\begin{array}{c}\text { Group I } \\
\text { Apple vinegar }\end{array}$} & \multicolumn{2}{|c|}{$\begin{array}{c}\text { Group II } \\
\text { EDTA }\end{array}$} & \multicolumn{2}{|c|}{$\begin{array}{c}\text { Control group } \\
\text { Saline }\end{array}$} & \multirow{2}{*}{$P$ value } \\
\hline & Mean \pm SD & Median & Mean \pm SD & Median & Mean \pm SD & Median & \\
\hline Cervical & $52.58^{\mathrm{Aa}} \pm 0.9$ & 52.59 & $52.13^{\mathrm{Aa}} \pm 1.14$ & 52.47 & $59.83^{\mathbf{A b}} \pm 4.17$ & 60.09 & $<0.001$ \\
\hline Middle & $50.89^{\mathrm{Ba}_{ \pm}} 1.47$ & 51.35 & $49.83^{\mathrm{Ba}_{ \pm}} 1.48$ & 50 & $54.26^{\mathbf{B b}} \pm 2.48$ & 53.57 & $<0.001$ \\
\hline Apical & $49.48^{\mathrm{Ca}_{ \pm}} 0.63$ & 47.4 & $50.89^{\mathrm{Bb}} \pm 1.47$ & 49.25 & $52.82^{\mathrm{Bc}} \pm 2.34$ & 51.9 & $<0.001$ \\
\hline$P$ value & $<0.001$ & & $<0.001$ & & $<0.001$ & & \\
\hline
\end{tabular}

Capital letters denotes significance in the same group. Small letters denote significance between groups. 


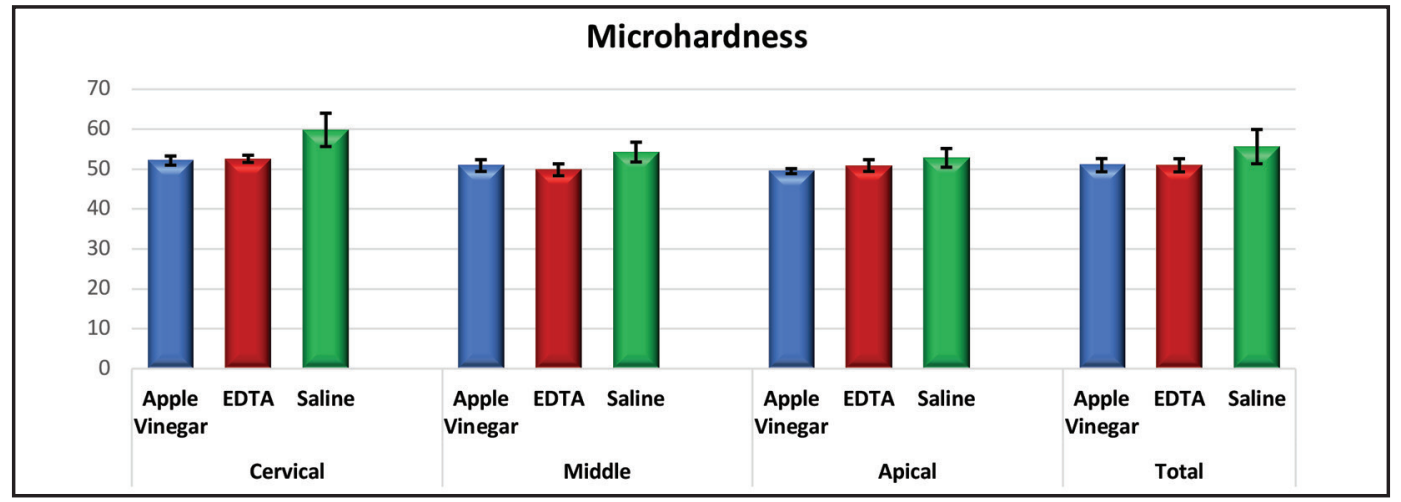

Figure (4) Bar chart representing the mean of microhardness scores comparing the three studied group (Group I (Apple Vinegar), II (EDTA) and control group (Saline)) at different levels, and total score.

\section{DISCUSSION}

Endodontic treatment is important to prevent unnecessary extractions, as it is performed to remove inflamed or non-vital tissues through disinfection, cleaning and sealing with a biocompatible rubbery material. Therefore, saving natural teeth, getting rid of the pain, help retaining esthetics, function and keeping future options for implants or bridges to be done $^{(20)}$

Chemical irrigants can cause dentinal erosion of the root canal as well as, peritubular and intertubular dentine may suffer from surface dissolution, that in sequences can affect tensile strength, fracture resistance, microhardness of radicular dentine, which can lead to vertical fracture of the teeth. Natural irrigants derived from plant extract are used now as an alternative for chemical irrigants, to enhance covalent collagen crosslinking and trying to increase mechanical properties of radicular dentine. Moreover, it has medicinal properties, antioxidants, bactericidal or bacteriostatic properties and immune enhancement ${ }^{(21)}$.

In this study, the crowns of single rooted mandibular premolars were decapitated at the cementoenamel junction, this was performed to standardize the samples and reduce human variables ${ }^{(21)}$.

Root canal preparations were done using M3 ProGold, as they are made from controlled memory wire. This NiTi metallurgy was developed to provide greater flexibility and cyclic fatigue resistance, allowing them to be used safely and efficiently ${ }^{(22)}$.

In conjunction to rotary mechanical preparation of root canals, $2 \mathrm{ml}$ of $2.6 \% \mathrm{NaOCl}$ was used as a primary irrigation for $1 \mathrm{~min}$. As it increases the permeability of radicular dentine to chelating agents, dissolves collagen, reduce bacterial count and causes oxidation of the organic portion of radicular dentine ${ }^{(23)}$. The use of NaOCL was limited to 1 min, because longer use can affect dentinal tissue negatively, causing unwanted microcrack formation, decrease in flexural strength, microhardness and fracture resistance ${ }^{(24)}$.

As the purpose of this research was to see how apple vinegar affected fracture resistance and microhardness in radicular dentine, it was used as a final rinse in one of the experimental groups and $17 \%$ EDTA in the other group. Apple vinegar was selected as it is more capable for removing smear layer from intraradicular dentine when used as a final rinse, specially at the apical third compared to $17 \%$ EDTA $^{(12)}$. The amount and time were selected to be $5 \mathrm{ml}$ for $3 \mathrm{~min}$, as longer time exposures can cause dentinal erosion and affect mechanical properties of radicular dentine negatively, while malic acid found in apple vinegar is highly acidic that causes better demineralizing effect in a shorter period. ${ }^{(25)}$. 
Measuring Fracture Resistance was done using Universal Test Machine and microhardness tests were made with Vickers, as Vickers readings are extremely accurate, only one indenter can be used for all surface treatments, it can measure whether the material is soft or hard under varying loads ${ }^{26,27)}$. Measuring microhardness at 3 portions (cervical, middle and apical) of radicular dentine were done at the $0.2 \mathrm{~mm}$ level from the root canal walls. As less than $0.2 \mathrm{~mm}$ can cause specimen fracture and more than $0.2 \mathrm{~mm}$ can result in incorrect microhardness readings, ${ }^{(28)}$.

Regarding the results of fracture resistance; there was a statistically significant decrease in fracture resistance in group II (EDTA) compared to Group I (Apple vinegar) as well as the control group (saline), however, there was no statistically significant difference between Group I (Apple vinegar) and control group (saline). This may be attributed to that EDTA is a chelating agent which means that it can form four or six bonds with metal calcium ions, it forms chelates with both transition and main groups. It is like a claw like material, that bind and stick to calcium ions. Moreover, any change or defect in the original amount of calcium ions can affect the characteristics of dentine as hardness, fracture resistance, permeability and solubility characteristics. Due to its demineralizing action by acting on inorganic portion of radicular dentine EDTA can cause disturbance in the microstructure of radicular dentine and dentinal erosion ${ }^{(29)}$.

The inclusion of malic acid in apple vinegar's ingredients, on the other hand, is responsible for its biocompatibility; the ethyl alcohol created is converted to acetic acid under the influence of particular microbes, a process known as acetification., It also contains magnesium, phosphorus, and potassium, among other minerals. The removal of dentine calcium ions is known to be caused by ionic exchange, adsorption, and chelation. ${ }^{(29)}$. This is supported by another study that showed that apple vinegar was more effective in removal of smear layer without affecting calcium content of intraradicular dentine compared to $17 \%$ EDTA. In the study it was shown that the highest calcium content found in the apple vinegar more than the EDTA is due to the mechanism by which calcium ions are removed, that apple vinegar removed it by acetification, while EDTA removed calcium ions by chelation ${ }^{(30)}$.

Regarding the results of microhardness, it was found at both cervical and middle levels; there was no statistically significant difference between Group I (Apple vinegar) and Group II (EDTA), while there was a statistically significant difference between both experimental groups (I, II) and the control group (saline). However, at the apical level; the results showed there was a statistically significant difference in microhardness between the two main experimental groups (I, II) as well as the control group (saline).

This may be related to the fact that the coronal and middle thirds of the canals are larger than the apical third, which increases the irrigating solution effectiveness in the coronal and middle, resulting in fewer obstacles in removing the smear layer in the coronal and middle thirds as compared to the apical third. Although, there is always decrease in the effect of irrigating solution in the apical third, may be due to sclerosed dentine and decrease in dentinal tubules diameter, that causes difficulty in flow of irrigating solution ${ }^{(31)}$. Although, other studies showed that apical portion have marked variations, low amount non-collagenous proteins, irregular secondary dentine, cementum like tissue, that is why EDTA don't cause such pronounced effect apically, because it acts on the non-collagenous proteins and the smear layer ${ }^{(31)}$.

While there was no statistically significant difference in total microhardness between the two main experimental groups, there was a statistically significant decrease in microhardness in the experimental groups as compared to the control group. Another study found that apple vinegar eliminates the smear layer in the same way that 17 percent EDTA does ${ }^{(16)}$ EDTA is a chelating agent, it influences 
physical and chemical qualities such as microhardness and flexural strength by acting on the inorganic portion of the smear layer ${ }^{(32)}$ Other researches, on the other hand, have found that EDTA solution has a negative softening effect on the dentine calcified components, lowering dentine microhardness by acting on the inorganic portion of dentine, which accounts for $70 \%$ of dentine ${ }^{(28)}$

\section{CONCLUSIONS}

Regarding fracture resistance, apple vinegar shows better results than $17 \%$ EDTA. While, it is comparable to $17 \%$ EDTA in microhardness of radicular dentine.

\section{RECOMMENDATIONS}

Further studies are recommended to investigate the clinical outcome of apple vinegar in-vivo.

\section{ACKNOWLEDGEMENT}

The authors express their sincere thanks to Dr. M. Abbas laboratory for his support in measuring fracture resistance and microhardness of radicular dentine.

\section{CONFLICT OF INTEREST}

There was no conflict of interest declared by the authors.

\section{DECLARATION OF FUNDING}

This study was self-funded.

\section{REFERENCES}

1. Siqueira JF, Jr., Pérez AR, Marceliano-Alves MF, Provenzano JC, Silva SG, Pires FR, et al. What happens to unprepared root canal walls: a correlative analysis using micro-computed tomography and histology/scanning electron microscopy. Int Endod J. 2018;51:501-8.

2. Bóveda C, Kishen A. The Role of Modern Technologies for Dentin Preservation in Root Canal Treatment. In: Plotino G, editor. Minimally Invasive Approaches in Endodontic Practice. Cham: Springer International Publishing; 2021. p. 1-32.
3. Prada I, Micó-Muñoz P, Giner-Lluesma T, Micó-Martínez P, Muwaquet-Rodríguez S, Albero-Monteagudo A. Update of the therapeutic planning of irrigation and intracanal medication in root canal treatment. A literature review. J Clin Exp Dent. 2019;11:e185-e93.

4. Boutsioukis C, Arias-Moliz MT. Irrigating Solutions, Devices, and Techniques. In: Boutsioukis C, Arias-Moliz MT, editors. Endodontic Materials in Clinical Practice. 1st ed: Springer; 2021.p. 133-80.

5. Mahant R. A Contemporary Overview of Endodontic Irrigants - A Review. austin journal of dental applications. 2014;1:105-15.

6. Mohammadi Z, Jafarzadeh H, Shalavi S, Kinoshita JI. Unusual Root Canal Irrigation Solutions. J Contemp Dent Pract. 2017;18:415-20.

7. Biel P, Mohn D, Attin T, Zehnder M. Interactions between the Tetrasodium Salts of EDTA and 1-Hydroxyethane 1,1-Diphosphonic Acid with Sodium Hypochlorite Irrigants. J Endod. 2017;43:657-61.

8. Mohammadi Z, Giardino L, Palazzi F, Asgary S. Agonistic and Antagonistic Interactions between Chlorhexidine and Other Endodontic Agents: A Critical Review. Iran Endod J. 2015;10:1-5.

9. Dioguardi M, Gioia GD, Illuzzi G, Laneve E, Cocco A, Troiano G. Endodontic irrigants: Different methods to improve efficacy and related problems. Eur J Dent. 2018;12:459-66.

10. Fernandes Zancan R, Hadis M, Burgess D, Zhang ZJ, Di Maio A, Tomson P, et al. A matched irrigation and obturation strategy for root canal therapy. Sci Rep. 2021;11:4666.

11. Arias-Moliz MT, Ruiz-Linares M, Ferrer-Luque CM. Irrigating solutions in root canal treatment. Endod Pract Today. 2019;13:131-46.

12. Safwat H, Nour El Deen M, Bastawy H. Evaluation of Smear Layer Removal and Calcium Ions Concentration in Intraradicular Dentin Treated with Apple Vinegar (SEM Study). Al-Azhar Dental Journal for Girls. 2017;4:279-87.

13. Elsheikh HM, Elhousiny MA. Effect of Using Boswellia Sacra Extract as Final Irrigant on Removal of Smear Layer. Al-Azhar Dental Journal for Girls. 2021;8:55-8.

14. Yagnik D, Serafin V, A JS. Antimicrobial activity of apple cider vinegar against Escherichia coli, Staphylococcus aureus and Candida albicans; downregulating cytokine and microbial protein expression. Sci Rep. 2018;8:1732. 
15. Mohanty S, Ramesh S, Muralidharan NP. Antimicrobial efficacy of apple cider vinegar against Enterococcus faecalis and Candida albicans: An in vitro study. Journal of Advanced Pharmacy Education and Research. 2017;7:137-41.

16. Abdelghany ME, Kamel WH, Bastawy HA. Efficacy of Apple vinegar as Final Irrigating Solution in Removing Smear Layer Using XP-Endo Finisher File. Al-Azhar Dental Journal for Girls. 2020;7:95-8.

17. Katsuda Y, Niwano Y, Nakashima T, Mokudai T, Nakamura K, Oizumi S, et al. Cytoprotective Effects of Grape Seed Extract on Human Gingival Fibroblasts in Relation to Its Antioxidant Potential. PLOS ONE. 2015;10:e0134704.

18. Vidal CM, Zhu W, Manohar S, Aydin B, Keiderling TA, Messersmith $\mathrm{PB}$, et al. Collagen-collagen interactions mediated by plant-derived proanthocyanidins: A spectroscopic and atomic force microscopy study. Acta Biomater. 2016;41:110-8.

19. Shetty S, Tejaswi S, Ambikathanya U, Mittal A. Comparative Evaluation of the Antimicrobial Efficacy of Different Irrigating Solutions on Endodontic Pathogens-An In Vivo Study. J Evol Med Dent Sci. 2021;10:789-93.

20. Al-Nuaimi N, Ciapryna S, Chia M, Patel S, Mannocci F. A prospective study on the effect of coronal tooth structure loss on the 4-year clinical survival of root canal retreated teeth and retrospective validation of the Dental Practicality Index. Int Endod J. 2020;53:1040-9.

21. Cochrane S, Burrow MF, Parashos P. Effect on the mechanical properties of human and bovine dentine of intracanal medicaments and irrigants. Aust Dent J. 2019;64:35-7.

22. Pedullà E, Savio FL, La Rosa GRM, Miccoli G, Bruno E, Rapisarda S, et al. Cyclic fatigue resistance, torsional resistance, and metallurgical characteristics of M3 Rotary and M3 Pro Gold NiTi files. Restorative dentistry \& endodontics. 2018;43.

23. Lima Nogueira BM, da Costa Pereira TI, Pedrinha VF, de Almeida Rodrigues P. Effects of Different
Irrigation Solutions and Protocols on Mineral Content and Ultrastructure of Root Canal Dentine. Iran Endod J. 2018;13:209-15.

24. Souza EM, Quadros JdRP, Silva EJ, De-Deus G, Belladonna FG, Maia-Filho EM. Volume and/or time of $\mathrm{NaOCl}$ influences the fracture strength of endodontically treated bovine teeth. Brazilian dental journal. 2019;30:31-5.

25. Rath PP, Yiu CKY, Matinlinna JP, Kishen A, Neelakantan P. The effect of root canal irrigants on dentin: a focused review. Restor Dent Endod. 2020;45:e39.

26. Bilgi PS, Shah NC, Patel PP, Vaid DS. Comparison of fracture resistance of endodontically treated teeth restored with nanohybrid, silorane, and fiber reinforced composite: An in vitro study. J Conserv Dent. 2016;19:364-7.

27. Broitman E. Indentation Hardness Measurements at Macro-, Micro-, and Nanoscale: A Critical Overview. Tribology Letters. 2016;65:23.

28. Massoud SF, Moussa SM, Hanafy SA, El Backly RM. Evaluation of the microhardness of root canal dentin after different irrigation protocols (in vitro study). Alexandria Dental Journal. 2017;42:73-9.

29. Mittal A, Dadu S, Yendrembam B, Abraham A, Singh N, Garg P. Comparison of new irrigating solutions on smear layer removal and calcium ions chelation from the root canal: An $<$ i>in vitro</i> study. Endodontology. 2018;30:55-6.

30. Elmessiry A, Darrag A, Ghoneim W. Effect of different irrigation solutions and techniques on push-out bond strength of resin-based sealer. Tanta Dental Journal. 2019;16:46-8.

31. Tabatabaei FS, Torshabi M. Effects of Non-Collagenous Proteins, TGF- $\beta 1$, and PDGF-BB on Viability and Proliferation of Dental Pulp Stem Cells. J Oral Maxillofac Res. 2016;7:e4.

32. Muana H, Nassar M, Dargham A, Hiraishi N, Tagami J. Effect of smear layer removal agents on the microhardness and roughnessof radicular dentine. Saudi Debtal journal.2020;1013-9052 